\title{
Protective Effect of Camellia sinensis on Methotrexate-Induced Small Intestinal Mucositis in Mice
}

\author{
Samuel Brito de Almeida ${ }^{1}$, Manuel Carlos Serra Azul Monteiro ${ }^{2}$, Ana Valêska Pinto de Lima ${ }^{3}$, \\ Dalgimar Beserra de Menezes ${ }^{4}$, Sandra Maria Nunes Monteiro ${ }^{5 *}$ \\ ${ }^{1}$ Center of Endocrinology, Metabolism and Nutrition Studies of Brazilian Northeast, Medicine Faculty/Federal University of Ceará, \\ Fortaleza, Brazil; ${ }^{2}$ Department of Physiology and Pharmacology/Medicine Faculty/Federal University of Ceará, Fortaleza, Brazil; \\ ${ }^{3}$ Medicine/Health Sciences Center, University of Fortaleza, Fortaleza, Brazil; ${ }^{4}$ Department of Pathology and Forensic Medicine/ \\ Medicine Faculty/Federal University of Ceará, Fortaleza, Brazil; ${ }^{5}$ Department of Nutrition/Health Sciences Center/Federal University \\ of Rio Grande do Norte, Natal, Brazil. \\ Email: smnmonteiro@gmail.com
}

Received November $14^{\text {th }}, 2013$; revised December $14^{\text {th }}, 2013$; accepted December $21^{\text {st }}, 2013$

Copyright (c) 2014 Samuel Brito de Almeida et al. This is an open access article distributed under the Creative Commons Attribution License, which permits unrestricted use, distribution, and reproduction in any medium, provided the original work is properly cited. In accordance of the Creative Commons Attribution License all Copyrights (C) 2014 are reserved for SCIRP and the owner of the intellectual property Samuel Brito de Almeida et al. All Copyright (c) 2014 are guarded by law and by SCIRP as a guardian.

\section{ABSTRACT}

Background: Green tea has been used as a daily beverage for several years. Anti-inflammatory effect of tea has also been depicted in different papers. Therefore we had set forward this study to examine the potential antiinflammatory activity of green tea in small intestine mucositis experimental models. Aims: Evaluation of antiinflammatory effects of green tea on mice. Materials and Methods: Green tea decoction (20\%) was prepared by soaking $20 \mathrm{~g}$ of green tea in $100 \mathrm{ml}$ boiled water separately, soaked for 2 minutes and thereafter filtered. Inflammatory activity was induced using methotrexate $(2.75 \mathrm{~g} / \mathrm{kg} / 24 \mathrm{~h} s c)$, and a protecting effect of mucositis condition was investigated by vitamin $\mathbf{E}$ and Camellia sinensis decoction. Study Design: An experimental study was approved by an Animal Ethical Commitee. Results: Green tea decoction (20\%) has shown significant anti-inflammatory effects (65\% and $70 \%)$ on methotrexate-induced acute mucositis model. In villous atrophy Green tea decoction (10\% and $20 \%)$ has shown no protecting action at different intestinal segments. But at intestinal crypt hyperplasia, green tea decoction has shown $65.74 \%$, as compared to mucositis group. An increase of apoptotic bodies were acchieved at MTX group, CS reduced this occurrence. Conclusion: Taken together, our data indicate that green tea $(20 \%)$ has a potential anti-inflammatory compared vitamin $E$ antioxidant action and corroborates with the current trend of tea being promoted as "health drink". However more pharmacological and biochemical assays is necessary to elucidate mechanisms.

\section{KEYWORDS}

Mucositis; Vitamin E; Camellia Sinensis; Morphometry; Mice; Cathechins

\section{Introduction}

The intestinal epithelium forms a dynamic system of continuous proliferation, differentiation and cell death. In the crypt compartment, stem cells and proliferating cells produce new epithelial cells [1]. Collectively, the epithelial cells maintain a high barrier function. The use of cytostatic drugs like methotrexate in cancer treatment may severely impair intestinal epithelial function resulting in

*Corresponding author. mucositis. This is clinically manifested by malabsorption, malnutrition, dehydration and diarrhea [1]. The gastrointestinal tract is particularly vulnerable to these effects, presumably because of high cell proliferation and turnover rates [2]. The mucosal damage is known to be induced initially as a consequence of loss of mitotic cells in the epithelium [3] leading to villi flattening and absorptive dysfunction [4]. The antimetabolite methotrexate is widely used in cancer chemotherapy, causing intestinal mucosal injury, by inhibition of dihydrofolate re- 
ductase, which is required for DNA synthesis and cell division [5]. The intestinal cells journey from the crypt to the villous tip is completed in 2 - 5 days and terminates with the cell remotion by apoptosis and/or exfoliation [6,7]. At highly metabolically and proliferative active tissue like the intestinal epithelium, Vitamin E protects membranes from damage by free radicals, and in mice is required to stem cell proliferation and oxide-reduction reactions $[8,9]$. Others chemical compounds such as cathechins, present at green tea could counteract an oxidative event reducing inflammatory pattern. Methotrexateinduced enteropathy in rat small intestine, especially in jejunum, is characterized by diarrhea, villous atrophy and impaired digestive and absorptive function [10], Additionally, MTX-induced injury has been exacerbated by malnutrition and of elemental diet consumption [11]. Thus, the aim of this study was to evaluate the effect of Camellia sinensis and vitamin E supplementation on the intestinal barrier function in this experimental model.

\section{Methods}

Chemicals were obtained from the following manufacturers: Methotrexate (MTX; Immunex Corporation; Seatle, WA); Camellia sinensis (laboratório Brasmed, Brazil); Vitamins E (Laboratório Sundow). Diets included total nitrogen content around 10\% - 13\%. All groups consumed commercial chow (Fri-Ribe-SP, Brazil).

Animal experiments were performed with permission of the Experimental Ethical Committee of Federal University of Ceará-Brazil; and the protocol was complied with the Occupational Health and Safety in the Care and Use of Research Animal, National Research Council (National Academic Press, 1977). Male adults Swiss Mus musculus ( $\mathrm{n}=32,35$ - $40 \mathrm{~g}$ ) from Pharmacology and Physiology Department, Federal University of Ceará, were used throughout the experiments. Animals were housed in individual metabolic cages, maintained under a 12 hours light-dark cycle, and controlled access to a standard palletized diet and water. Mice were monitored daily, for signs of diarrhea, metabolic control and mortality. An experimental model of intestinal mucositis in rats as described previously [12], was modified and adapted for mice.

Control (PBS, phosphate buffer solution, via gavage), methotrexate (2.75 mg/kg/24 h sc) and Camellia sinensis decoction and vitamin E (10 IU/animal/24 h via gavage) groups ( $n=8$ /group) were treated during three days. Tea decoction (20\%) was prepared by soaking $20 \mathrm{~g}$ of green tea in $100 \mathrm{ml}$ boiled water separately, soaked for 2 minutes and thereafter filtered. This filtrate was designated as "green tea decoction". The dose of this decoction orally administered to each mice was $0.1 \mathrm{ml} / 10 \mathrm{~g}$ of body weight. Initial pilot study suggested that $20 \%$ of green tea preparation had given significant results, than 10\% green tea. Therefore, we have decided to set forward our study with $20 \%$ green tea decoction. Since the maximum mucosal damage caused by MTX occurs after 72 hours after the MTX administration, and MTX+CS (methotrexate plus Camellia sininsis) or vitamin E (methotrexate plus vitamin $\mathrm{E}$ ), all the mice were sacrificed (at $4^{\text {th }}$ day), under general anesthesia $(50 \mathrm{mg} / \mathrm{kg}$ ketamine +10 $\mathrm{mg} / \mathrm{kg}$ xilazine $\mathrm{im}$ ). Intestines of the mice were removed for histological examination just after they have been sacrificed, and put in formalin after being washed with iced isotonic saline solution. Histopathological changes in the intestinal cells were examined via qualitative blindly histological evaluation by a pathologist. On the histological examination performed after the routine tissue processing, villus length and the crypt depth were morphometrically evaluated analyzing the tissue sections stained with hematoxylin eosin (H\&E), measurements were done on 40 villi from 40 crypts per animal. To examine apoptotic events, sections were examined under light microscopy. Counts of apoptotic cells and apoptotic bodies were performed using $40 \times$ objective. Cells were scored as apoptotic if they exhibited cellular shrinkage with concurrent cytoplasmic eosinophilia, nuclear pyknosis, and fragmentation with associated apoptotic bodies. Areas of marked lymphocytic infiltration or necrosis were not used for counting.

\section{Statistical Analyses}

Statistical analysis was performed using GraphPad Prism 5.01 (GraphPad Software, San Diego, CA) and consisted of a two-way ANOVA with Bonferroni post hoc tests when appropriate. And groups were tested for homogeneous variance then used a Student's $t$ test. Data are presented as mean \pm standard error of the mean. For daily monitored parameters, repeated measures two-way ANOVA was performed. For all, $p<0.05$ was considered significant.

\section{Results}

\subsection{Histomorphologic Approach}

Mucositis condition was achieved at mice treated with methotrexate $(2.75 \mathrm{mg} / \mathrm{kg} / \mathrm{day} \mathrm{sc})$. Subcutaneous route was chosen, to avoid direct intestinal insult, but induce a systemic delivery of metabolites inhibitors of cell proliferation at barrier function, reproducing an inflammatory small intestine status (Panel 1(b)) when compared with PBS treated group (Panel 1(a)-Foliaceous villi with many goblet cells). No changes were found at ileum segments at all groups. In addition, vitamin E and CS supplemented animals presented more goblet cells at vil- 
lous (Panels 1(c) and (d)_black single arrows). Methotrexate induced mild goblet cell depletion, and villi atrophy in the small intestine during a period of epithelial damage and apoptotic events (Panel 1(b)—white doubleheaded arrow).

\subsection{Intestinal Morphometry}

Similarly, in this present study showed at Figure 1 (duodenum) and Figure 2 (jejunum), villus length was found shortened in the MTX group, at duodenum (D; $364.8 \pm$ 19.90 vs $437 \pm 19.92 \mu \mathrm{m})$ and at jejunum $(\mathrm{J} ; 363.3 \pm$ $20.65 \mu \mathrm{m}$ as compared to the control group (426.0 \pm $15.14 \mu \mathrm{m} ; p<0.01)$. Crypt depth was found as hyperplasic feature at mice with intestinal mucositis. CS (D; $155 \pm$ 6.88; J, $126.8 \pm 5.65 \mu \mathrm{m})$ and VITE (D; $241.5 \pm$
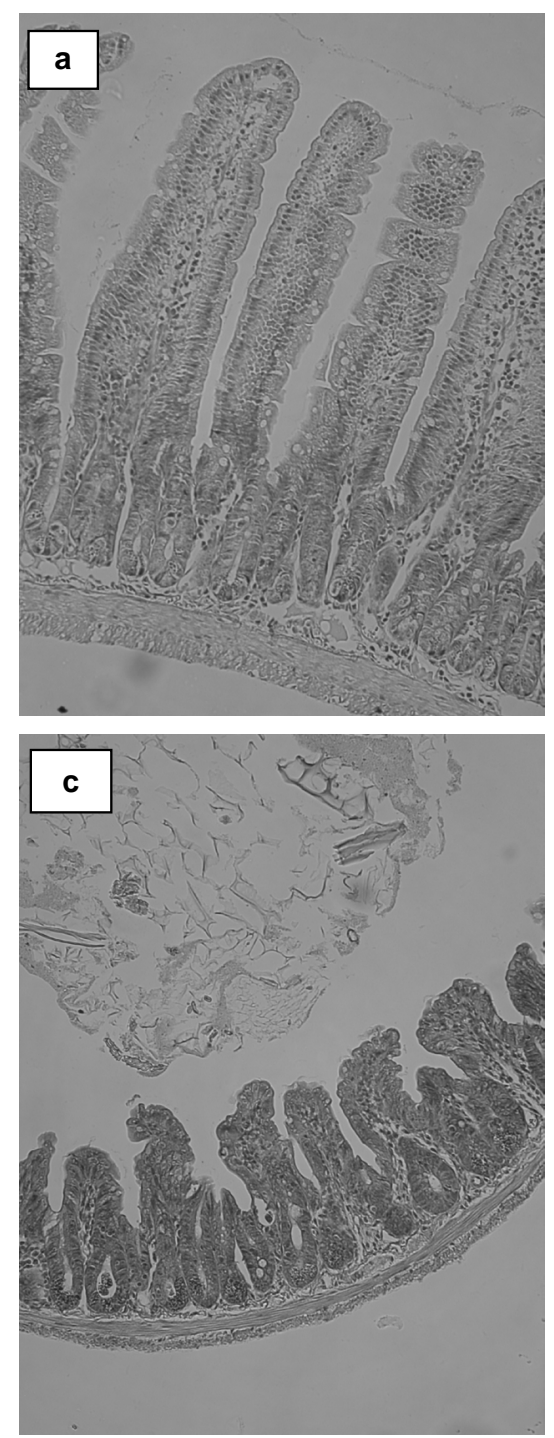

$16.2 \mathrm{~J} ; 122 \pm 5.78 \mu \mathrm{m})$ supplementation did not alter villous atrophy when compared as control (D; $98.0 \pm 5.26$ $\mu \mathrm{m}$; J vs $114.0 \pm 4.76 \mu \mathrm{m})$, however reestablished crypt morphometry. Methotrexate $(9.3 \pm 0.68)$ administration induced a marked increase of apoptotic bodies at duodenum compared with control mice (0.88 \pm 0.17$)$. Camellia sinensis $(1.64 \pm 0.78)$ but not vitamin $\mathrm{E}(9.2 \pm 0.61)$ ameliorates cellular death induced by methotrexate. Shortening in the villus length, as well as the decrease in the mucosal thickness and villus length/crypt ratio, is likely to occur in the MTX-induced mucositis models in rats. Villous/crypt length ratios of control group were 3.8 at duodenum and 4.27 at jejunum; in opposite to MTX animals (1.89 at duodenum and 2.42 at jejunum), in agree with intestinal morphometry.
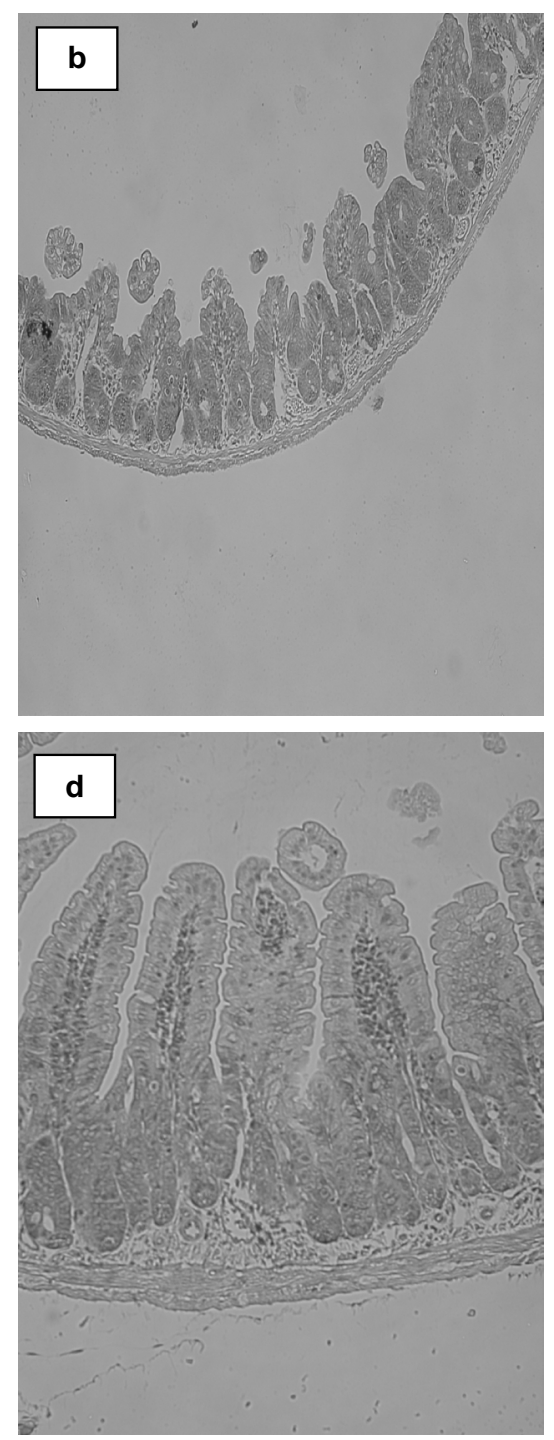

Panel 1. The morphology and histopathology of the jejunum treated with PBS or methotrexate (MTX; 2.5 mg/kg, s.c.) (a)

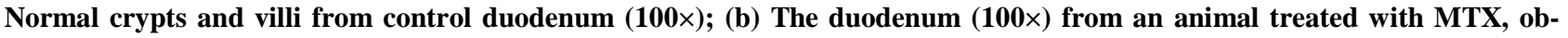
serve the blunted villi and hyperplasic crypts compared with the control. Photomicrographs of supplemented groups; (c) Vitamin E; and (d) Camellia sinensis at mucositis condition. 


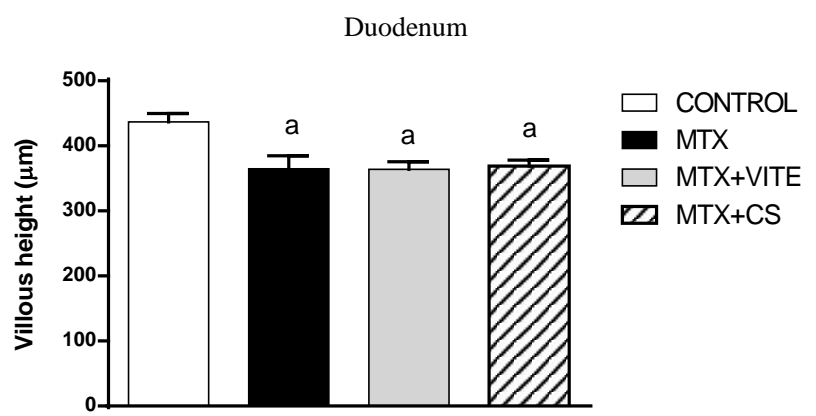

a $(p<0.05$, Control vs MTX)

b $(p<0.05$, MTX vs other group)

(a)

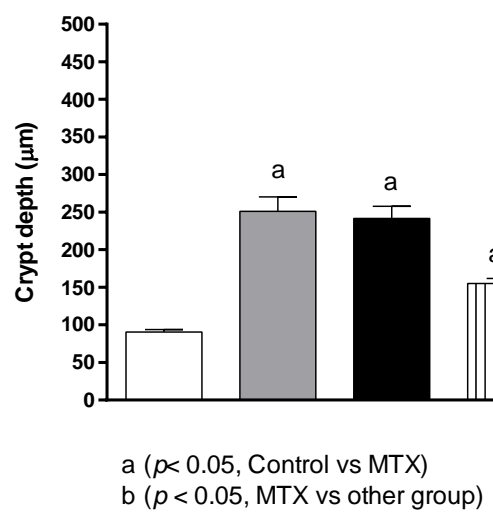

(b)

Figure 1. Morphometric analysis of vitamin E supplementation and CS decoction in mice by methotrexate-induced intestinal mucositis (MTX) at duodenum. (a) Villous height; and (b) Crypt depth $(\mu \mathrm{m})$ of animals treated with MTX (2.75 $\mathrm{mg} / \mathrm{kg} / 24 \mathrm{~h} \mathrm{sc}$ ) or PBS (control) during 3 days. Mice were supplemented with vitamins E (10 IU/animal) at the same period of MTX administration. Morphometry was performed with optical microscopy using an eyepiece (scale of 1 $\mathrm{mm})$. Results are presented as mean \pm SEM, ${ }^{\#} p<0.05$, MTX compared with control, and ${ }^{*} p<0.05$, MTX compared with vitamins groups (ANOVA, Bonferronis's test).

\subsection{Apoptotic Events}

At green tea $20 \%$ decoction group, no mortality was achieved, similar to those results at ulceration ear mice experimental model induced by MTX. As expected, MTXinduced mucositis mice, presented (Figure 3) more intestinal cell death $(9.30 \pm 0.16$ apoptotic bodies/field/ sample) when it compared to control $(0.78 \pm 0.02)$. Vitamin E supplementation do not alter apoptotic events (8.60 \pm 0.07), however CS supplementation (2.40 \pm 0.03 apoptotic bodies/field/sample) reduces intestinal cell death mainly at jejunum at inflammatory condition.

\section{Discussion}

Apart from fundamental basic research investigating

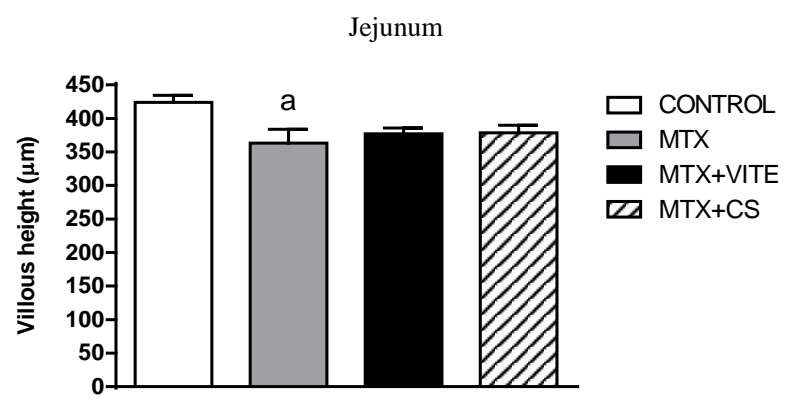

a $(p<0.05$, control vs MTX)

(a)

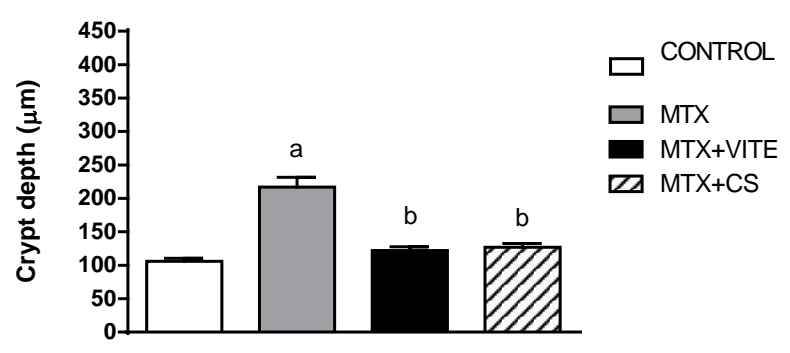

a $(p<0.05$, control vs MTX)

b $(p<0.05$, MTX vs CS or VITE)

(b)

Figure 2. Morphometric analysis of vitamin E supplementation and CS decoction in mice by methotrexate-induced intestinal mucositis (MTX) at jejunum. (a) Villous height; and (b) Crypt depth $(\mu \mathrm{m})$ of animals treated with MTX $(2.75$ $\mathrm{mg} / \mathrm{kg} / 24 \mathrm{~h} \mathrm{sc}$ ) or PBS (control) during 3 days. Mice were supplemented with vitamins E (10 IU/animal) at the same period of MTX administration. Morphometry was performed with optical microscopy using an eyepiece (scale of 1 $\mathrm{mm})$. Results are presented as mean $\pm \mathrm{SEM},{ }^{\#} p<0.05$, MTX compared with control, and ${ }^{*} p<0.05$, MTX compared with vitamins groups (ANOVA, Bonferronis's test).

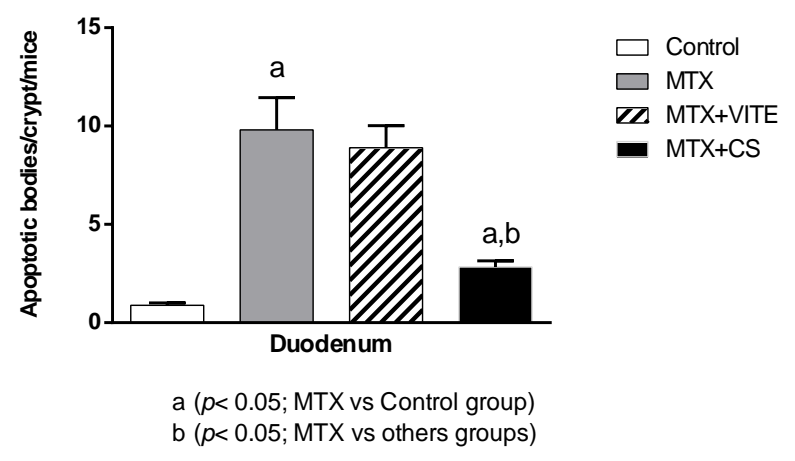

Figure 3. Duodenal apoptosis analysis in mice with intestinal mucositis induced by methotrexate (MTX, $2.75 \mathrm{mg} / \mathrm{kg}$ / 24 h s.c). Mice were supplemented with and E (10 IU/animal). Legends: Control (PBS); MTX (methotrexate), CS (Camellia sinensis), VITE (vitamin E). Morphometry were performed by optical microscopy using an eyepiece (scale of $1 \mathrm{~mm}$ ), HE staining. Results are presented as mean $\pm \mathrm{SEM}$, ${ }^{\#} p<0.05$ (MTX compared with control, and ${ }^{*} p<0.05$, MTX compared with others groups (ANOVA, Bonferronis's test). 
mechanisms by which the latter stages of cancer can be inhibited, there are no nutraceuticals that have advanced to the point of clinical trial testing. However, this is a promising area of basic research in cell lines and in animal models. At intestinal mucositis induced by methotrexate administration, the toxic effects are not considered to be a result of direct action on the gastrointestinal tract tissues but rather to be the consequence of an inhibition in dihydrofolate reductase synthesis. This enzyme is required to maintain the intracellular pool of tetrahydrofolate during purine and thymidine synthesis. The chemical and morphologic changes in the small intestine may be triggered by crypt cell damage [13]. To minimize the side effects in patients undergoing chemotherapy, it is important to reduce mucosal damage and stimulate tissue repair. Such intestinal damage is reported to be prevented by some kinds of nutrients and growth factors. Plant products are in use for a long time in Ayurvedic and folklore medicine for the cure of ailments with minimal side effects and comparable efficacy. Green tea term (Camellia sinensis) nominate a great variety of Thernaceae family plants, including 520 species, endemic in tropical and sub-tropical areas of Asia and South America. Green tea decoction has a medicinal use in these countries due to beneficial and potent antioxidants properties. As a medicinal beverage, it is recommended to nauseas, vomiting and at diarrhea condition. Antibacterial action had been used at infections and at wounds treatment [14]. Aside from the pluripotent effects of green tea polyphenols, exist an increasing list of molecular processes, including oxidative stress [15]. Cathechins, mainly (-)-epigallocatechin-3-gallate (EGCG), represent the largest group of flavonoids (flavan-3-ols) in the tea plant, in particular in fresh leaves and green tea. Injected and orally administered green tea cathechins, in vitro, significantly decreased bacterial LPS-induced alveolar bone desorption and IL-1 expression in the gingiva of BALB/c mice $[15,16]$. Initially in mucositis development, direct DNA damage caused by the chemotherapy agents might lead to cellular death in the basal epithelium and submucosal cells, but clonal cell death occurs in only small part of the damaged cells. Vitamin E and CS protection occurred probably due a retardation of inflammatory process at progenitors intestinal crypt cells [17-19]. On the other hand, the methods used at present study are insufficient to explain completely the intensive damage at mucositis; but present results demonstrated clearly an amelioration of intestinal barrier morphology. Gastrointestinal impaired function could be positively modulated by Camellia sinensis [20]. At green tea $20 \%$ decoction group, no mortality was achieved, similar to those results at ulceration ear mice experimental model induced by MTX. These results agree with our finds at intestinal mucositis model. However, at this challenge, green tea treatment did not affect the main effect of methotrexate (arresting cell division in S-phase) [21]. Data suggest that an offer of CS or vitamin E supplementation could treat villous atrophy, cells crypt hyperplasia and increase of intestinal apoptosis, induced by MTX challenge.

\section{Conclusion}

Marked intestinal barrier function disruption was caused by a methotrexate administration. In addition, a protecting effect of Camellia sinensis decoction at small intestine of mice with mucositis, was achieved similarly to antioxidant action of vitamin E. Probably, cathechins compounds of this green tea, initiate an antioxidant protection. However more pharmacological and biochemical assays are essential to elucidate protector mechanism, and potential active compounds.

\section{Acknowledgements}

Scientific Initiation Program (CNPq; University of Fortaleza), and a histology technician José Ivan R. De Souza by his valuable work.

\section{REFERENCES}

[1] M. Verburg, I. B. Renes, H. P. Meijer, J. A. J. M. Taminiau, H. A. Büller, A. W. C. Einerhand and J. Dekker, "Selective Sparing of Goblet Cells and Paneth Cells in the Intestine of Methotrexate-Treated Rats," American Journal of Physiology Gastrointestinal Liver Physiology, Vol. 279, No. 5, 2000, pp. G1037-G1047.

[2] J. S. Trier and T. H. Browning, "Morphologic Response of the Mucosa of Human Small Intestine to X-Ray Exposure,” Journal of Clinical Investigation, Vol. 45, No. 2, 1996, pp. 194-204.

[3] D. M. Keefe, A. G. Cummins, B. M. Dale, D. Kotasek, T. A. Robb and R. E. Sage, "Effect of High-Dose Chemotherapy on Intestinal Permeability In Humans," Clinical Sciences, Vol. 92, No. 4, 1997, pp. 385-390.

[4] J. S. Trier, "Morphologic Alterations Induced by Methotrexate in the Mucosa of Human Proximal Intestine," Gastroenterology, Vol. 4, 1962, pp. 407-423.

[5] M. Verburg, I. B. Renes, D. J. Van Nispen, et al., "Specific Responses in Rat Small Intestinal Epithelial mRNA Expression and Protein Levels during Chemotherapeutic Damage and Regeneration,” Journal of Histochemistry and Cytochemistry, Vol. 50, No. 11, 2002, pp. 1525-1536. http://dx.doi.org/10.1177/002215540205001113

[6] M. Bjekjernes and H. Cheng, "Clonal Analysis of Mouse Intestinal Epithelial Progenitors,” Gastroenterology, Vol. 116, No. 1, 1999, pp. 7-14. http://dx.doi.org/10.1016/S0016-5085(99)70222-2

[7] J. A. J. M. Tamineau, D. G. Gall and J. R. Hamilton, "Response of the Rat Small-Intestine to Methotrexate," Gut, Vol. 21, No. 6, 1980, pp. 486-492. http://dx.doi.org/10.1136/gut.21.6.486

[8] I. L. Cameron, J. Muñoz, C. J. Barnes and W. E. Hard- 
man, "High Dietary Level of Synthetic Vitamin E on Lipid Peroxidation, Membrane Fatty Acid Composition and Citotoxicity in Breast Xenograft and in Mouse Host Tissue,” Cancer Cell International, Vol. 3, 2003, p. 3.

[9] S. Subramaniam and C. S. Shyamala Devi, "Vitamin E Protects Intestinal Basolateral Membrane from CMF-Induced Damages in Rat," Indian Journal of Physiology and Pharmacology, Vol. 39, No. 3, 1995, pp. 263-266.

[10] R. A. Warden, S. N. Rhiannon, J. L. Francis, P. R. Dunkley and E. V. O’Loughlin, "Vitamin A Deficiency Exarcerbates Methotrexate-Induced Jejunal Injury in Rats," Journal of Nutrition, Vol. 127, No. 5, 1997, pp. 770-776.

[11] C. D. Tran, G. S. Howard, P. Coyle, J. C. Philcox, A. M. Rofe and R. N. Butler, "Dietary Supplementation with Zinc and a Growth Factor Extract Derived from Bovine Cheese Whey Improves Methotrexate-Damage Rat Intestine," American Journal of Clinical Nutrition, Vol. 77, No. 5, 2003, pp. 1296-1303.

[12] B. A. Carneiro-filho, I. P. F. Lima, D. H. Araújo, M. C. Cavalcante, G. H. P. Carvalho, G. A. C. Brito, V. Lima, S. M. Nunes-Monteiro, F. N. Santos, R. A. Ribeiro and A. A. M. Lima, "Intestinal Barrier Function and Secretion in Methotrexate Induced Rat Intestinal Mucositis,” Digestive Diseases and Sciences, Vol. 49, No. 1, 2004, pp. 65-72. http://dx.doi.org/10.1023/B:DDAS.0000011604.45531.2c

[13] T. Horie, T. Li, K. Ito, S. Sumi and T. Fuwa, “Aged Garlic Extract Protects against Methotrexate-Induced Apoptotic Cell Injury of IEC-6 Cells,” Journal of Nutrition, Vol. 136, Supplement 3, 2006, pp. 861S-863S.

[14] K. Tsurui, Y. Kosakai, T. Horie and S. Awazu, "Vitamin A Protects the Small Intestine from Methotrexate-Induced Damage in Rats," Journal of Pharmacology and Experimental Therapy, Vol. 253, No. 3, 1995, pp. 1278-1284.
[15] E. M. Varoni, G. Lodi, A. Sardella, A. Carrassi and M. Iriti, "Plant Polyphenols and Oral Health: Old Phytochemicals for New Fields," Current Medicinal Chemistry, Vol. 19, No. 11, 2012, pp. 1706-1720. http://dx.doi.org/10.2174/092986712799945012

[16] P. R. Bhatt, K. B. Pandya and N. R. Sheth, "Camellia sinensis: The Medicinal Beverage: A Review,” International Journal of Pharmaceutical Sciences Review and Research, Vol. 3, No. 2, 2010, pp. 3-6.

[17] A. L. Molan, Z. J. Liu and R. Tiwari, "The Ability of Green Tea to Positively Modulate Key Markers of Gastrointestinal Function in Rats,” Phytotherapy Research, Vol. 24, No. 11, 2010, pp. 1614-1619. http://dx.doi.org/10.1002/ptr.3145

[18] T. R. Ziegler, M. E. Evans, C. Fernandez-Estivariz and D. P. Jones, "Trophic and Cytoprotective Nutrition for Intestinal Adaptation, Mucosal Repair, and Barrier Function,” Annual Review of Nutrition, Vol. 23, 2003, pp. 229-261. http://dx.doi.org/10.1146/annurev.nutr.23.011702.073036

[19] S. Subramaniam and C. S. Shyamala Devi, "Vitamin E Protects Intestinal Basolateral Membrane from CMF-Induced Damages in Rat,” Indian Journal of Physiology and Pharmacology, Vol. 39, No. 3, 1995, pp. 263-266.

[20] A. L. Molan, Z. J. Liu and R. Tiwari, "The Ability of Green Tea to Positively Modulate Key Markers of Gastrointestinal Function in Rats,” Phytotherapy Research, Vol. 24, No. 11, 2010, pp. 1614-1619. http://dx.doi.org/10.1002/ptr.3145

[21] A. A. Mansour, M. A. Salam and Y. M. Saad, "Mice (Mus musculus) Genome Responses to Methotrexate (MTX) and Some Plant Extracts," Life Science Journal, Vol. 9, No. 4, 2012, pp. 4881-4886. 